Psychiatria clin.10: 1977; 256

\title{
Index autorum
}

Bellak, L. 102

Berger, E. 123

P. Pethô, B. 173 Presslich, O. 233 Reiter, L. 7

140

158 Ringel

E. 85 Schuster

P. 233 Sonneck

G. 85

131 Springer

A. 140

158 Strotzka

H. 7 Temkov

I. 64 Wytek

R. 233 Ziolko

H.U. 214

Berner, P. 4, 5

Ciompi, L. 96

Picker, F. 199

Friedrich, M.H. 114

Gabriel, E. 4, 5, 140, 158, 233

Häfner, H. 27

Hoffmann, I. 214

Opgenoorth, E. 233

Peters, U.H. 186 